\title{
LIS, Rat Strain
}

National Cancer Institute

\section{Source}

National Cancer Institute. LIS, Rat Strain. NCI Thesaurus. Code C114342.

This rat comes from Lister stock at the Lister Institute in the 1920s, but the derivation

origin is unknown. It has a white body coat color and black coat color over the head. 